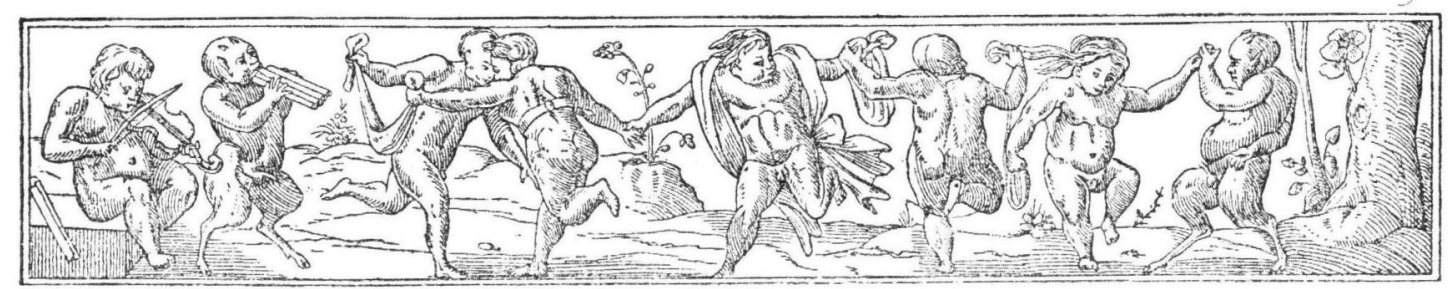

\title{
De Schoorsteenen van het Amsterdamsch Stadhuis
}

DOOR

A. W. WEISSMAN.

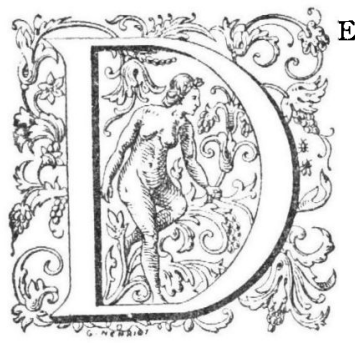

E gewoonte, om de schouwen in vertrekken te versieren, werd hier te lande in de $15^{\mathrm{e}}$ eeuw algemeen. Tot het laatst der I 8 e eeuw hield men haar in eere; zelfs toen de schouwen voor de zoogenaamde "Engelsche schoorsteenen" begonnen plaats te maken, liet men die maar zelden geheel onversierd, tenzij de kostbaarheid van het gebezigde marmer de hulp van den beeldhouwer overbodig kon doen achten.

JACOB VAN CAMPEN heeft, bij het ontwerpen van het Stadhuis voor Amsterdam, het bestaande gebruik gevolgd, en de schouwen der voornaamste verdieping van zijn ontwerp zóó geordonneerd, dat QuELLINUs en zijn helpers gelegenheid vonden, hun kunst te toonen.

Of deze bouwmeester ook de bedoeling heeft gehad, de boezems der schouwen ieder met een schilderij te versieren, blijkt niet. Wat echter wel vast staat is, dat JACOB VAN CAMPEN sedert 1654 zich niet meer met den bouw van het Stadhuis bemoeid heeft; in de stukken komt na I December van dat jaar geen uitgave wegens hem vergoede reis- en verblijfkosten, noch wegens betaald honorarium meer voor. Ik vermoed, dat VAN CAMPEN met het Amsterdamsch stadsbestuur ongenoegen gekregen heeft over zijn houding jegens den wegens fraude in 1653 oneervol ontslagen stadssteenhouwer WILLEM DE KEYSER, aan 
welken kunstenaar hij de uitvoering der graftomben van TROMP en VAN GALEN had opgedragen. Wat hier echter van zij, in 1655 , toen de eerste schoorsteenstukken besteld en geplaatst zijn, is van JACOB VAN CAMPEN in de documenten geen sprake meer.

Wij beginnen onze wandeling door het Stadhuis op de pui, en, ons naar het noorden wendende, komen wij het eerst in de Justitiekamer. Hier zien wij tegenwoordig geen schouw meer, maar dat er een geweest moet zijn bewijst de plattegrond van het gebouw, die in het plaatwerk van DANCKERTS voorkomt. Die schouw vertoont daar twee kolommen, doch verdere bijzonderheden zijn uit den aard der zaak in een plattegrond niet te zien.

Een schoorsteenstuk schijnt hier nooit geweest te zijn, althans JAN VAN Dijk, die in $175^{8}$,alle de Schilderyen" op het Stadhuis aanwezig, beschreef, vermeldt in deze zaal alleen "een plafond, van drie bijzondere Stukken, geschildert door NiCOlaAs DE Helt STOKKade," hetwelk er tegenwoordig nog is.

Wij mogen dus aannemen, dat in 1808 deze schouw is weggebroken, en gissen, dat dit geschied is, wijl de versierselen, waarmede zij prijkte, in een koninklijk paleis minder passend werden geacht, wellicht omdat zij betrekking hadden op de lijfstraffelijke rechtspleging.

Wel maakt de staat der beeldhouwwerken, die A. W. KROON in zijn „Amsterdamsch Stadhuis" gaf, van geen schoorsteen in de Justitiekamer melding, maar deze schrijver, die geen beoefenaar der bouwkunst was, heeft bij het opstellen van dezen staat zich blijkbaar hier en daar vergist.

Zoo noemt hij, als gemaakt voor Burgemeesterskamer, behalve de marmeren kapiteelen voor den schoorsteen, nog twee ,ronde kapiteelen van Avendersteen," die daar niet meer te zien zijn, en waarvan het niet duidelijk is, waarvoor zij ooit gediend kunnen hebben, daar de oude plattegronden geen andere zuilen dan die der schouw vertoonen. Ik ben geneigd aan te nemen, dat dit de kapiteelen van de Justitiekamer geweest zijn, en zou dan ook den post van $f$ 630, die voor beeldhouwwerk aan een schoorsteen betaald is, met dit vertrek in verband willen brengen. Immers de versiering van den schoorsteen in Burgemeesterskamer, "voorstellende den triomf van Fabius Maximus," is met $f 500$ betaald, en een tweeden schoorsteen heeft deze zaal nimmer gehad.

De kamer „der Heeren XXXVI Raden," ook wel de Vroedschapskamer genoemd, grenst ten noorden aan de Justitiekamer. Deze zaal, die ook de tusschenverdieping omvat, is een der fraaiste van het gebouw. Men ziet er twee schoorsteenen, wier boezems elk door vier zuilen gedragen worden. Deze zuilen van rood marmer vertoonen de Composiet-orde in haar van wit marmer uitgevoerde kapiteelen en basementen. 
Wanneer men de lijst der beeldhouwwerken van QUELlijn, zooals KROON die geeft, raadpleegt, dan vindt men daarop voor deze zaal vier ronde en vier halve kapiteelen met honden-, leeuwen- en wolvenkoppen vermeld. Doch de schoorsteenen hebben ieder vier zuil- en vier pilaster-kapiteelen, waaraan geen koppen te zien zijn, daar zij getrouw naar de Composiet-orde van ScamozzI zijn gevolgd.

Maar de caissons van het gewelf vertoonen wel honden-en leeuwenkoppen, zoodat deze met de ,kapiteelen" van 1654 bedoeld moeten zijn.

De kapiteelen der schoorsteenen zullen wel in 1656 gemaakt zijn, toen ook QUELLIJN $f 976$ voor de friezen betaald kreeg. Symon BosBoom stond toen aan het hoofd der stads-steenhouwerij, en deze meester, die ScamozzI vertaald heeft, was zeker wel de man, om zulke kapiteelen te modelleeren.

De friezen van QUELLIJN hebben in hoofdzaak een ornamenteel karakter; toch ontbreken daarin de zinnebeelden niet, zooals de sfinxen, als toespeling op de keuze, die de Vroedschap ieder jaar in Januari ter vervulling der regeeringsambten had te doen, en de honden, die de trouw aan de stad beduiden.

Is het van den aanvang af de bedoeling geweest, de schoorsteenen van schilderijen te voorzien? Het antwoord op deze vraag zal wel moeielijk te geven zijn. Dat de eigenlijke schoorsteenboezem, schuin oploopend, boven het bekronend fronton uitkomt, wijst er op, dat de oorspronkelijke ontwerper een smallere schouw heeft willen maken, en dat pas later tot den tegenwoordigen vorm besloten is. $\mathrm{Na} 1654$ heeft JACOB VAN CAMPEN zich niet meer met het Stadhuis ingelaten, doch is STALPAERT daar de leider geworden. Van hem moet de ordonnantie dezer schouwen afkomstig zijn, die nu juist niet geacht kan worden, door goeden smaak uit te munten. Immers de zware, bijna vierkante boezem is in geen verhouding tot de fijne zuilen die hem dragen.

Wij weten ondertusschen niet, welke de bedoeling van JACOB VAN CAMPEN geweest is, daar van zijn teekeningen niets is overgebleven, en het prentwerk van DANCKERTS alleen den in 1662 bestaanden toestand geeft.

Den I 2 den Juli 1657 ontving GOVERT FLINCK $f 2500$ voor het noordelijke schoorsteenstuk, dat SALOMO's gebed om wijsheid voorstelt. Het zal wel kort daarna geplaatst zijn.

JAN BRONKHORST kreeg in ${ }_{1} 659$ opdracht om het zuidelijke schoorsteenstuk te maken, dat JETHRO en MOZES, de wet aan de oversten gevend, voorstelt. Hij kreeg er slechts $f$ rooo voor, en toen hij het 14 Januari I 660 gereed had, eischten de heeren, dat hij het zou "verbeteren", zonder daarvoor extra betaling te verlangen.

MiChiel CoOmans schilderde in 1658 onder het stuk van FLINCK VONDEL's vers:

cud-Hobland 1907 . 
Door SALOMo's gebed en Offer God behagen, Werd hem de Wijsheid 's nachts beloofd uit 's Hemels Troon, Met eenen Rijkdom, Eer en veelgewenschte Dagen.

Waar Wijsheid raden mag daar spant de Staet de Kroon.

Onder het zuidelijke stuk stond niets. Want VAN DiJK zegt: „Ik vinde dit Vaars daartoe gemaakt te zijn, maar is niet daaronder geschreven:

De groote Mozes geeft aan 't Volk des Hemels Wetten,

Ten eind het zijne Ziel niet ruukloos zouw besmetten,

Dit was een Baken voor het dwalende geslacht.

De Wetten zijn een Zuil, en schragen 't land met Macht."

Waarom dit gedicht achterwege werd gelaten, vermeldt vaN DIJK niet. Misschien was het den heeren te democratisch en wilden de XXXVI Raden niet met het volk, noch met een "dwalend geslacht" vergeleken worden.

In de i $8 \mathrm{e}$ eeuw werd het stuk van BronkHorst aan FERDINAND BoL toegeschreven. VAN DIJK vermeldt althans uitdrukkelijk, dat JAN BRONKHORST, en niet REMBRANDT's leerling, de maker is, wat door de Thesauriersrekening bevestigd wordt.

Over de schilderij van FLINCK is VAN DIJK uitvoeriger. "'t Is wel een van zijn beste stukken, die uit zijn Penceel voortgekomen zijn; 't is om zo te spreeken zonder Verve, of onvervig; hij heeft het hemelsblauw alleen aan de Hemelsche Wijsheid en den Hogepriesterlijke Rok gebruikt, maar den Koning SALOMON een Goudlaakens kleet gegeven, en geene van de drie Verven, die op Gods bevel tot de Tente der tezamenkomste gewijd waren, als Purper, Scharlaken en Heemelsblauw gebezigd, wel begrijpende, dat deze drie Verven aan geen Perzoonen buiten den Hogepriester pasten om te dragen. Een Stuk Schilderij, dat niet alleen waardig is om gepreezen te worden, maar dat alle HistorieSchilders, zo wel weegens Ordonnantie, Groeping, Houding en Couleuren tot een voorbeeld dienen kan."

Inderdaad verdient de schilderij den lof, dien vaN DijK haar toebrengt.

De schoorsteen in de Weeskamer, die door Jonische zuilen en pilasters wordt gedragen, is waarschijnlijk door VAN CAMPEN ontworpen. Immers QUELLIJN makkte reeds in $\mathrm{I} 654$ de fries, die met kinderkopjes versierd is, als toespeling op de bestemming van het vertrek. In datzelfde jaar sneed hij ook de festoenen en de wapens (sedert weggehakt) der Weesmeesteren, welker ordonnantie geheel in den geest van JACOB VAN CAMPEN is.

Het schoorsteenstuk verbeeldt Lycurgus, die zijn neef tot zoon aanneemt, en is geschilderd door CORNELIS HOLSTEyn, die zich hier een goed colorist heeft getoond en ook in de verdeeling van het licht en bruin gelukkiger is geweest dan anders. 
De twee vertrekken aan de noordzijde van het gebouw, die thans volgen, hebben schouwen, die veel eenvoudiger zijn, dan de overige. Hier waren de Assurantiekamer en de Desolate Boedelkamer gevestigd, twee colleges, die minder loog op de ranglijst stonden dan de andere. De versiering der schouwen bepaalt zich tot consoles en zuiver ornamenteel bewerkte friezen, die niet op den staat van QUELLIJN voorkomen. Alleen de in eikenhout gesneden festoenen en wapens die de schoorsteenstukken omgeven vindt men daar.

Het schoorsteenstuk wordt door VAN DIJK, wat de Assurantiekamer aangaat, dus verklaard, In de Assurantiekamer voor den Schoorsteen staat een schilderij, alwaar Thezeus het kluwen, dat hem uit den Doolhof van Minos geholpen heeft, weder teruggeeft. De verslagen Minotaurus leit voor het Doolhof in het verschiet." Het stuk is gemerkt: „Willem Brassemary i657." Omtrent dezen meester zegt VAN DIJK, dat hij ook STRIJKER heette, doch verder gaan zijn mededeelingen niet dan ,van wien ik nergens iets beschreven vinde."

Dan vervolgt hij: „In de Kamer van den Desolaten Boedel staat ook een stuk voor den Schoorsteen van THEODORUS DE KEYZER 1657, verbeeldende een Maagd in het Wit gekleed, met een Kroontje op 't Hoofd aan een oever van de Zee, met eenige Maagden, die Goed op een Wagen op- of afladen, voor haar knielt een Man met Wijngaarts Bladen omwonden, wijzende op een Tafel met Fruit, aan den Oever geplaatst. Ik voor mij kan hier geen andere zin in vinden, als daar Thezeus, Ariadne te Naxos aan land gezet en verlaten hebbende, door Bachus wert opgenomen, waardoor de desolate toestand van Ariadne door Bachus hersteld wierd."

Het is mij niet gelukt, een handteekening op dit stuk te vinden. De kamer, op het noorden tegenover de Nieuwe Kerk gelegen, is slecht verlicht, en de schilderij nogal donker. Een THEODORUS DE KEyser is als schilder niet bekend, wel THOMAS DE KEYSER, die kort daarna als stadssteenhouwer zijn leven zou eindigen en die vooral vóór I 640 als portretschilder vermaard was. Wanneer deze schilderij werkelijk van THOMAS DE KEyser is, dan heeft zij waarde niet slechts als zijn eenige historiestuk, maar ook omdat zij blijkbaar onder REMBRANDT's invloed is ontstaan.

VAN DIJK heeft het onderwerp niet begrepen. Het is ODYSSEUS, die NAUSIKAA aanspreekt, nadat hij als schipbreukeling is komen aanspoelen. De gezellinnen van NAUSikaA laden het waschgoed op den wagen. In een Desolate Boedelkamer past zulk een stuk zeer goed.

De schoorsteen in de Rekenkamer vertoont dezelfde ordonnantie als die der Weeskamer, maar hier is geen marmer, doch zandsteen gebruikt. QuellijN heeft de fries in 1656 voor $f$ I 68 gemaakt, en daarenboven nog voor $f$ I 70 aan 
houtsnijwerk geleverd. Daarvan is niets meer te zien; het zou kunnen wezen, dat het achter den boezem, dien koning LoDEwijk NAPOLEON liet maken, nog verscholen is. Een schoorsteenstuk wordt door VAN DIJK niet genoemd. Wat men nu ziet is een Italiaansch landschap van omstreeks $\mathrm{I} 800$.

In de kamer van Schepenen Extraordinaris, ook wel Schepensvertrek genoemd, zien wij een schoorsteen, aan den vorigen vrij wel gelijk. Een schoorsteenstuk was hier aanvankelijk niet. Doch toen de noordelijke schouw uit de Schepenskamer in het midden der $\mathrm{i} 8 \mathrm{e}$ eenw werd weggebroken en door een meer moderne vervangen, werd het schoorsteenstuk naar Schepensvertrek overgebracht, waar het niet goed in den boezem past, omdat het te hoog is.

VAN DiJk zegt er van: "De schilderij is van den ouden JAN LIEvENSE, en wel van zijn beste, zijnde niet zoo overvloedig dik in de Verve." Deze mededeeling is niet juist, want het stuk is, volgens de Resolutiën van Thesaurieren, door JURRIAAN OVENS geschilderd, die er in I66I een bedrag van $f 252$ voor ontving. MELCHIOR FOCKENS noemt het dan ook in 1662 als een werk van dien meester. Hoe VAN DIJk er toe kwam, JAN LiEvensz voor den schilder aan te zien, is onbegrijpelijk. Sedert hebben allen, die zich met kunstgeschiedenis bezig hielden, zijn fout herhaald. Het is te hopen, dat men Lievensz nu niet langer met de vederen van Ovens zal oppronken.

Jammer, zeer jammer is het, dat de prachtige schoorsteen in Schepenskamer nu reeds weldra honderd jaar door den daarvoor geplaatsten troon aan het oog wordt onttrokken. Het zou gewenscht zijn, aan dien troon een andere plaats te geven, of, indien daartegen bezwaren mochten bestaan, hem alleen dan op te slaan, wanneer het hof op het paleis verblijf houdt. De groote kunstwaarde van wat verborgen is zou zulk een maatregel in allen deele rechtvaardigen.

Van de fries, waar QUELLIJN „de historie der kinderen Israëls" verbeeldde, is nu niets te zien. Maar de reliëfs aan de zijden, nu alleen zichtbaar, geven waarborg voor de schoonheid van het overige.

Het „overheerlijke stuk" dat FERDINAND Bor, voor deze schouw schilderde, heeft geen der thans levenden aanschouwd. In welken toestand zal het verkeeren, nu het een eeuw verborgen is geweest? Zullen de muizen het niet doorknaagd hebben, zal het niet op andere wijze beschadigd zijn? Inderdaad, het moet voor den dag gebracht worden.

JAN vaN DIJK zegt er van: "In de Kamer der Heeren Scheepenen vinden wij voor de grote Schoorsteen de Historie daar Moses, (na mijn gedagten) ten tweede maal met de Tafelen der Wet van den Berg afkomt, en dezelve aan het Volk vertoont, die daarvoor alle eerbiedigheid bewijzen, een overheerlijk stuk, 
geschilderd door Ferdinandus Bol. De groote J. van Vondel heeft daartoe dit Vaars gemaakt, hoewel niet daaronder geplaatst als bij veele vorige.

\begin{abstract}
„Hebreeuwsche Mozes heeft de Wet van God ontfangen, Waarmede hij naar 't Volk van boven weederkeert, Dat hem eerbiedig groet en welkomt met verlangen. De vrije staat luikt op, als 't Volk de Wetten eert."
\end{abstract}

Dat dit vers niet geplaatst werd, moet men misschien aan de te democratische opvatting van den dichter wijten.

De schoorsteenen in de vertrekken der Commissarissen van Kleine Zaken en in die van Thesaurieren Extra-ordinaris hadden in de $18_{\mathrm{e}}$ eeuw geen schilderijen, daar VAN DIJK er geen melding van maakt. Deze schouwen, welke dezelfde gedaante hebben als die van de Rekenkamer, zijn van Jonische zuilen en pilasters voorzien. Op de staten van QuELLIJN worden alleen de friezen en de houten festoenen op de hoeken der boezems vermeld. Koning Lodewijk NAPOLEON heeft de boezems laten versieren door stucwerk in Empire-stijl.

De Secretarie is in $\mathbf{1} 808$ het meest veranderd. Dit vertrek, dat de zuidzijde van het Stadhuis inneemt, werd niet alleen door een vloer in twee verdiepingen verdeeld, doch ook door een muur in twee kamers veranderd. De schoorsteenen werden toen gesloopt. De oostelijke vooral moet fraai geweest zijn, want alleen voor de ,marmeren kolommen met loof en bloemen" kreeg QUELLIJN $f$ 300. Aan andere versieringen, waarschijnlijk voor de friezen en de boezems, werd nog $f$ rooo ten koste gelegd, zoodat hier meer dan de helft besteed werd, van hetgeen voor Burgemeesterskamer, de rijkste van het gebouw, is uitgegeven. Reeds in 1654 en $1655 \mathrm{kwam}$ al dit werk gereed, zoodat het onder de leiding van VAN CAMPEN zal zijn gemaakt.

Uit den plattegrond van DANCKERTS blijkt, dat slechts de oostelijke schoorsteen zuilen had, doch dat de westelijke in den geest van die der Desolate Boedelkamer was behandeld. VAN DIJK spreekt van één schoorsteen, „daarvoor staat het Portret van de Koningin van Vrankrijk, MARIA DE MEdiCIS." Dit stuk van Honriorst ziet men nu in de wachtkamer van den Burgemeester op het Prinsenhof.

Naar het oosten gaande bereiken wij nu de Thesaurie Ordinaris, het vertrek op den hoek van den Dam en de Kalverstraat. Daar de Thesaurieren na de Burgemeesteren de hoogste macht hadden, is de schoorsteen in hun kamer rijk versierd.

De schachten der wit marmeren zuilen zijn met loofwerk omwonden, de pilasters springen op zijde naar buiten en de fries prijkt met velerlei ornament. Reeds in 1654 was dit alles gereed, en wij mogen daarom JACOB VAN CAMPEN voor 
den ontwerper houden. Maar de omgeving van het schoorsteenstuk is door QUELLIJN eerst in 1656 uit eikenhout gesneden. Blijkbaar is zij een navolging van de ordonnantie, die JACOB VAN CAMPEN reeds in 1654 voor de Weeskamer had gegeven.

Het schoorsteenstuk, door NICOLAAS DE HEIT STOCKADE, verbeeldt, volgens VAN DIJK „het Koornhuys van Egipten, alwaar de Onderdaanen niet alleen haar Goud, Zilver en Juweelen, maar ook zich en hunne Kinderen aanbieden, om Brood te mogen hebben."

VAN DIJK las daaronder nog, "het Vaars van J. VAN VONDEL."

Geheel Egypten brengt den Rijxvoogt Schat en Haven, En leeft nu zeeven jaar bij 't uitgereikte graan.

Het Vrije Volk, door noot, word 's Konings eyge Slaaven:

Eens Mans voorzichtigheit kan duizenden verzaân.

Toen koning LODEWIJK NAPOLEON dit vertrek tot slaapkamer bestemde heeft men het vers door overschildering aan het oog onttrokken, daar het $Z$. M. niet aangenaam kon zijn, te lezen, dat "het vrije volk, door nood, tot zijn slaven" was geworden.

Burgemeestersvertrek, waar de Oud Raad vergaderde, is aan den Dam gelegen, en komt geheel overeen met de reeds genoemde Vroedschapskamer of Raadszaal. De twee schouwen zijn van 1655 en dus waarschijnlijk wel door STALPAERT ontworpen.

De friezen der schoorsteenen prijken met kinderfiguurtjes, die verschillende zinnebeelden houden. Het zuidelijke schoorsteenstuk is van GoverT FLINCK, „zijnde de Historie van Marcus Curius, waarvan de verklaring door den grooten VONDEL, in het daaronder geschreven Vaars duidelijk uitgedrukt is.

Op Burgermeesters wagt mag Romen veilig slapen, Als Marcus Curius, het aangeboden gout Versmaande, zich vernoegt met een geregt van Raapen:

Zoo wort door Matigheid en Deugt een Staat gebout."

Wanneer dit stuk geschilderd is, staat niet vast. FLINCK stierf in I660, en het moet dus vóór dien tijd voltooid zijn geweest. Ik gis, dat het pas na "Salomo's gebed" is gemaakt, dat in 1657 gereed was. Misschien hebben de minder goede ervaringen, die men met JAN BRONKHORST had opgedaan, toen hem het tweede stuk voor de Raadzaal besteld was, de heeren er wel toe gebracht om zich voor het tweede stuk in Burgemeestersvertrek tot FERDINAND BoL te wenden. Volgens VAN DIJK is de "Aartsdichter Joost VAN DEN VONDEL" de maker van het vers, dat onder de schilderij staat en dat dus luidt:

Fabritius houdt stand in Pirrhus Legertenten, Het Goud verzet hem niet, noch schandelijke zucht, Noch Elefants gebriesch, noch felle dreigementen.

Zoo zwicht geen Man van Staat voor gaven noch gerucht." 
Wij komen nu in Burgemeesterskamer, het voornaamste vertrek van allen, en hebben dan onze wandeling door het Stadhuis volbracht.

Wanneer men den plattegrond van het gebouw beziet, dan wordt men aanstonds getroffen door de volkomen symmetrie, welke alleen door den aanleg van Burgemeesterskamer wordt verbroken. JACOB vAN CAMPEN, die als klassiek meester veel aan volmaakte symmetrie hechtte, moet zich, in zijn oorspronkelijk ontwerp, Burgemeesterskamer als tegenhanger van de Justitiekamer hebben gedacht. Een bewijs daarvoor is te vinden in den plattegrond van DANCKERTS, waar de ingeschreven mat voor beide vertrekken 36 voet bedraagt, ofschoon zoowel het meten op dien plattegrond als in de werkelijkheid een verschil van 4 voet aangeeft.

Blijkbaar was het de bedoeling van den oorspronkelijken ontwerper, om beide vertrekken 40 voet lang te maken, doch is dit alleen bij de Justitiekamer gebeurd.

Op den plattegrond is de, thans verwijderde, schouw der Justitiekamer die zich aan de zijde der Vierschaar bevindt, duidelijk te zien. Zoo moet ook oorspronkelijk de schouw in Burgemeesterskamer zijn ontworpen, die dan dezelfde breedte zou hebben gekregen als die, welke men in de Weeskamer en de Thesaurie ziet, vertoonen.

Waarom werd in deze ordonnantie verandering gebracht? Omdat Burgemeesteren wenschten, dat een venster gemaakt zou worden, waardoor zij uitzicht in de Vierschaar konden hebben, als daar vonnissen werden voorgelezen. De rechtspraak geschiedde door Schout en Schepenen, zoodat de Burgemeesteren daar eigenlijk niets mede te maken hadden. De Schout had zelfs van ouds den voorrang boven Burgemeesteren. Om nu echter hun hoogheid ook bij de rechtspraak te doen gevoelen, plaatsten de Burgemeesteren zich voor hun geopend venster, als er in de Vierschaar recht werd gesproken.

Dit venster heeft de geheele ordonnantie van JACOB VAN CAMPEN bedorven, en het valt moeilijk aan te nemen, dat deze kunstenaar, die "un homme fascheux" was volgens HuxGeNs, zich zonder verzet tot het maken daarvan heeft laten vinden. Zeer mogelijk is, dat hij de verandering niet wilde maken, daarover ongenoegen gekregen heeft, en dat hij zich ook daarom na 1654 niet meer met het Stadhuis heeft ingelaten.

De heeren vonden in STALPAERT een meer meegaand man, en van hem zal dan ook wel de ordonnantie in Burgemeesterskamer afkomstig zijn, die allerminst gelukkig kan genoemd worden.

Immers om zoo goed mogelijk de symmetrie te herstellen, die door het maken van de vensteropening verbroken was, moest de ontwerper zijn toevlucht nemen tot een systeem van Korinthische pilasters die, daar het niet mogelijk 
was, ze van een hoofdgestel te voorzien, al heel weinig organisch in de ordonnantie zich voegen.

De plaatsing van deze pilasters moest daarenboven uit den aard der zaak zeer onregelmatig zijn. Ter wederzijden van het venster in de Vierschaar ziet men er een, die met twee andere tegen den zuidelijken muur overeenkomen. Om nu althans twee gelijke intercolumniën te verkrijgen, werd aan de oostzijde het pilastersysteem verdubbeld, een vrijheid, die JACOB VAN CAMPEN, als overtuigd Palladiaan, zeker zich niet heeft veroorloofd.

Tegenover het venster in de Vierschaar werd de schouw aangebracht, die, om niet te dicht tegen de Korinthische muurpilasters te komen, aanzienlijk smaller moest worden dan de overige op deze verdieping. De aansluiting van den boezem tegen de zoldering, in de andere vertrekken op ongezochte wijze tusschen de binten bewerkstelligd, leverde hier moeielijkheden op, die STALPAERT slechts wist te boven te komen, door aan den boezem een afzonderlijke kroonlijst te geven, en de zoldering daarboven te laten doorloopen. Niet slechts de man van het vak, maar ook de leek ziet aanstonds, dat de schoorsteen als het ware een hors d'oeuvre is.

De vraag, wanneer deze verandering gemaakt werd, kan niet met volstrekte zekerheid worden beantwoord. Op de lijst van QUELLIJN vindt men, dat in I654 voor dit vertrek werden gemaakt twee kapiteelen van marmer, twee ronde kapiteelen van Avender-steen, vier kleine festoenen van Avender-steen en twee groote imposten van marmer.

De twee kapiteelen van marmer zou men geneigd $z i j n$, voor die van den tegenwoordigen schoorsteen te houden, ware het niet, dat deze, daar zij volkomen naar de Korinthische orde zijn gevolgd, QuelLiJss kunstvaardigen beitel evenmin zullen hebben van noode gehad als de kapiteelen der andere schouwen, die dan ook niet de lijsten voorkomen.

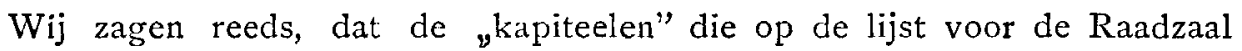
voorkomen, inderdaad caissons geweest zijn. Caissons ziet men echter in Burgemeesterskamer niet, en zij kunnen er ook nooit geweest zijn.

Ik houd het er voor, dat de kapiteelen wel voor den oorspionkelijken schoorsteen van Burgemeesterskamer zijn gemaakt, maar niet geplaatst. Wellicht heeft men ze, gelijk ik vroeger veronderstelde, voor den schoorsteen in de Justitiekamer, nu gesloopt, gebruikt.

De schoorsteenfries, voorstellende den triomf van Fabius Maximus en het snijwerk aan den schoorsteen zijn van ${ }^{6} 655$, waaruit ik meen te mogen afleiden, dat de verandering in de ordonnantie van dit vertrek in het begin van dit jaar moet hebben plaats gevonden. 
De aandacht verdient ook een post, die op de lijst van QukLLIJN voorkomt en die luidt: " 6 kertossen van Avender steen aan het gewelf," welke cartouches in ${ }^{6} 655$ geleverd zijn. De kamer heeft echter geen gewelf. Bezat zij er aanvankelijk een, en is ook de tegenwoordige zoldering pas in 1655 gemaakt? Of moeten wij hier denken aan een vergissing, en is het gewelf in Burgemeestersvertrek, grenzende aan Burgemeesterskamer, bedoeld? Ik houd het laatste voor het meest waarschijnlijk.

Ook de fries van Quellijn, die den triomftocht van Fabius Maximus voorstelt, heeft een merkwaardigheid. Deze optocht begint reeds op het oostelijke zijvlak en eindigt aan het westelijk eind van de voorzijde. Het westelijk zijvlak is gevuld met een voorstelling, welke niets met het eigenlijke onderwerp te maken heeft. Dit alles laat zich op ongezochte wijze verklaren, wanneer men aanneemt, dat de fries oorspronkelijk voor een breederen schoorsteen bestemd is geweest, doch in twee stukken geplaatst is, waarvan het kleinste het zijvlak en het grootste het voorvlak van de tegenwoordige schouw inneemt. Toen kwam men nog éćn zijvlak te kort, en daarvoor zou dan het relief gemaakt zijn, dat geheel afzonderlijk werd behandeld.

Voor den oorspronkelijken schoorsteen was een schilderij noodig, langer en minder hoog, dan die men nu ziet. Immers het versmallen van den boezem heeft ook het verkorten van de Korinthische zuilen ten gevolge gehad, opdat de goede verhouding zooveel mogelijk bewaard zou blijven.

Dit schoorsteenstuk nu meen ik te herkennen in de schilderij van REMBRANDT, die als "Scipio" verleden jaar in de Lakenhal te Leiden was tentoongesteld. Of het de schilderij zelf was of wel alleen een ontwerp daarvoor, blijve in het midden. Hetzelfde onderwerp is behandeld als wat VONDEL, toen LIEVENSz het stuk voor den veranderden schoorsteen gemaakt had, dus omschreef:

De zoon van Fabius gebiedt zijn eigen vader

Van 't paard te stijgen voor Stads Eer en Achtbaarheid.

Die kent geen bloed, doch eischt, dat hij ecrbiedig nader.

Zoo eert cen man van Staat het ambt hem opgelcid.

Ik veronderstel, dat HENDRIK VAN UvLENBURG, aan wien volgens de Stadsrekening in 1656 een bedrag van $f 630$ betaald werd voor het "schoonmaecken ende uythalen" der schilderijen op het Stadhuis, zijn zwager REMBRANDT VAN RIJN bij Burgemeesteren zal hebben aanbevolen. Of REMBRANDT werkelijk ecn bestelling heeft gekregen, blijkt niet. Doch in ieder geval was het stuk, toen de schoorsteen veranderd was, niet meer te gebruiken. En het is zeer verklaarbaar, dat, als de groote meester kort na 1655 , toen hij zijn stuk voltooid had, in geldelijke moeilijkheden geraakt, men zich tot JAN LIEvENSZ wendt om de schilderij te maken, die nog als schoorsteenstuk aanwezig is.

Oud-Holla na 1907. 
Deze schilderij is de eenige van Lievensz, voor een schoorsteen van het Stadhuis gemaakt, daar de andere, die tot dusver op naam van dezen meester stond, gelijk werd aangetoond, door JURRIAAN Ovens is vervaardigd.

VAN DiJK zegt dat het stuk voorstelt „de Historie van den Burgemeester Suesso, die, toen de Raad van Romen zijnen Vader Q. FabIUs Maximus als gezant aan hem afzond, en te Paard zittende zijn Zoon wilde naderen, dezelve zijnen Vader bevel gaf eerst van 't Paard te treeden, doordien er een wet was dat niemand, te Paard zittende, een Burgemeester mocht naderen om aan te spreken. De Vader gehoorzaamde dit bevel met eerbied, en bewees zijn Zoon de eer, die denzelven als Burgemeester toekwam."

Het voorval is beschreven zoowel door TiTUS LiviUs als door VALERIUS MAXimus. De eerste geschiedschrijver werd in de I7e eeuw veel gelezen, en dus zal de stof wel aan zijn werk ontleend zijn.

Vermoedelijk heeft men niet aan de schilders de keuze hunner onderwerpen overgelaten, maar zijn die hun, zoowel als QuELLIJN opgegeven. Het is eigenaardig, dat meest stoffen uit de Grieksche en Romeinsche geschiedenis werden gekozen, doch dat voor de Vroedschap, de Thesaurie en de Schepenskamer Oud-Testamentische onderwerpen werden genomen. Alleen in Burgemeesterskamer en Burgemeestersvertrek ziet men Romeinen; de Grieken treft men in de Weeskamer, de Assurantiekamer en de Desolate Boedelkamer aan.

Het bestellen dezer schilderijen is min of meer te hooi en te gras gegaan. Alleen met GOVERT FLINCK kwam men overeen, dat hij een bepaalde reeks van stukken zou leveren, doch eer hij nog aan het werk was gegaan, stierf hij. En den I I December I664 werd het besluit genomen, dat men voortaan geen schilderijen zou bestellen of aankoopen. Dit besluit heeft tengevolge gehad, dat de meeste schoorsteenen aan de zuidzijde van het gebouw, alleen die van Schepenkamer uitgezonderd, nimmer een schoorsteenstuk als versiering hebben gekregen.

De schoorsteenen van het Stadhuis bevinden zich nog in hun oorspronkelijken staat. Maar daar Koning LodewiJk NAPoLeon, toen hij in 1808 het gebouw als paleis liet inrichten, de schouwen met de groote open vuren niet geriefelijk vond, werden zij dichtgemaakt en plaatste men daarin de "Engelsche” schoorsteenmantels, die uit het nieuwe Stadhouderiijk Kwartier van het Binnenhof in den Haag waren gesloopt. Voor zoover dit noodig was werden nasst die schoorsteenmantels de spiegelglazen, uit dit gebouw af komstig, tegen de muren aangebracht.

Slechts één schouw werd buiten gebruik gesteld, namelijk de noordelijke van Burgemeestersvertrek, waaronder een deur naar Burgemeesterskamer werd gemaakt. 